\title{
Creativity in online gaming: Individual and dyadic performance in Minecraft
}

\author{
Alexander E. Voiskounsky ${ }^{\text {a }}$, Tatiana D. Yermolova ${ }^{\mathbf{a}}$, \\ Sergey R. Yagolkovskiy ${ }^{\mathrm{b}}$, Valeria M. Khromova ${ }^{\mathrm{b}}$ \\ a Psychology Department, Lomonosov Moscow State University \\ ${ }^{\mathrm{b}}$ School of Psychology, Faculty of Social Sciences, National Research University Higher School \\ of Economics, Moscow \\ *Corresponding author: E-mail: vae-msu@mail.ru
}

Objective: This study was designed to examine possible new aspects of creative activity related to virtual environments.

Design: The online gaming interface Minecraft was used to construct (on computer screens) complex structures such as buildings from ready-made blocks. Two modes were used: individual and dyadic. Participants ( $\mathrm{N}=49,29$ males and 20 females, 18 to 29 years old, recruited on a snow-ball basis) were required to build staying at a distance two complex structures - a ship and a house; each structure was required to be highly creative, i.e. unusual and never seen before. Creativity was evaluated not by the final structure but by the number of ideas generated by the participants and produced either in practice or verbally. Each participant participated once in an individual and once in a dyadic session; the partners were selected randomly. The participants' verbal activity and digital operations with the Minecraft interface were recorded using the FastStone Capture software package. All the ideas produced by participants were classified in accordance with the following criteria: type (conceptual, functional, selective, corrective, and intentional); level of the structure which the ideas referred to (the whole structure, a particular component of the structure, or an element of the structure); and the status of the verbalized ideas (implemented or unimplemented).

Results and Conclusion: The results show that participants produced significantly more ideas and took significantly less time to build the prescribed structure (a house or a ship) within the individual session compared to the dyadic session. The originality of their ideas was measured by two psychologists independently: the two measures turned out to be close $(\mathrm{r}=0.876)$; the number of original ideas produced during individual and dyadic sessions do not differ significantly. Analysis of the implementation of the ideas showed that, within the dyadic sessions, participants produced significantly fewer ideas which were subsequently implemented. For the most part they frequently dropped and left unimplemented ideas referring to the levels of either components or elements of the structure. The results also showed that intentions were the only type of ideas which, after 
being generated equally often in the individual and dyadic sessions, were more often left unimplemented in the group sessions, compared to the individual sessions.

Keywords: creativity, online gaming, dyadic vs. individual activity, idea generation, Minecraft

\section{Introduction}

\section{Creativity and new technologies}

Creativity can be regarded as an activity closely related to making new products in various forms. Its theoretical definition is related to the generation of novel ideas, products, or processes by an individual or group (e.g., George \& Zhou, 2001; Gruys, Munshi, \& Dewett, 2011). Creativity is a broad topic that is important at individual, social, economic, and cultural levels. Definitions of this psychological concept focus on various aspects, including biological, cognitive, and motivational (e.g. Amabile, 1996; Martindale, 1999). In the context of the psychometric approach to the study of creativity, it can be assessed by analyzing various parameters of the ideas that were generated (e.g. number of these ideas, their novelty, etc.). These ideas are regarded as products of individual or group creative activity. They partially depend on knowledge and expertise (e.g. Rich \& Weisberg, 2004).

At least three distinct forms of knowledge play an important role in producing creative ideas: 1) schematic knowledge, 2) associational knowledge, and 3) casebased knowledge (Hunter, Bedell-Avers, Hunsicker, Mumford, \& Ligon, 2008). At the same time, creative ideas include operational components, which transform relevant knowledge and expertise in the context of a given task or problem (e.g. Estes, Ward, 2002; Scott, Longergan, \& Mumford, 2005). Numerous cognitive processes determine the effectiveness of idea generation, such as problem construction, information gathering, conceptual combination, critical processing activities, etc. (Dailey \& Mumford, 2006; Kaufmann, 2003; Lubart, 2001; Russ, 2003).

The process of idea generation often takes place while individuals are interacting with computers or with other people via the Internet. New technologies today are forming frameworks in which creative work will be done in the near future. More and more types of work, including creative work, are already, or will soon be, mediated by digital technologies. More and more group work will be done with coworkers at a distant location. Future interfaces of mediated group-work settings are being designed and tested right now. In a way, the future comes through our current work. That means, we have a good opportunity today to develop, test, and approve or disapprove possible interfaces for group-work which will be performed in the future. We may call online interfaces favorable, or prospective, if they support collective styles of work which may be more productive than individual styles of work (except in cases where individuals are exceptionally productive persons).

The results reported in this paper derive from the development and testing of one hypothetical type of interface for joint work. The interface includes a joint work space for the team members presented on their digital screens, plus a voice interaction channel shared by team members. Team members at different locations may perform joint work, such as compilation of a document or a project description, design, and development of a visual object and its details, etc. This interface may 
be called a "zero-level interface" since it supports both individual and group work, but provides no advanced service: i.e., it provides no hints or prompts dealing with decision making; provides no lists of ideas (either previously mentioned, or known from previous studies, or prepared beforehand by the experimenters); and involves no discussion procedures such as, for example, suggestions that the most respected partner, or the person who has come up with the most recent idea, be given the lead (with or without interruptions).

The current paper presents results based on the performance of two groups of participants, who used ready-made building blocks to perform a construction task within a videogame environment. The final construction needed to be creative: i.e., unusual and original. To estimate the prospects for the interface, we compared the results of the group work (in our case, dyad work) with the results of individual work in the same setting. The current paper is a work-in-progress description; thus, it is restricted to an analysis of the results dealing with the productivity of the singles and dyads. Productivity is measured by the number of "ideas" produced either verbally or practically. Ideas refer to goals of creative actions, according to the psychological "personal meanings" theory of human thinking developed by Tikhomirov (1988). The number of goals, or ideas, is one of the parameters identified in Torrance-related studies of creativity: it refers to intellectual fluency and is universally accepted as a useful parameter.

\section{Creativity, computers and the Internet}

The Internet provides a variety of instruments for the realization of human creative potential. Networkers create new verbal/audio/visual content; they develop, consume, and improve various Internet resources and applications. These activities can influence the participants' intelligence and creativity. Greenfield (2009) states that Internet users score higher in verbal and non-verbal intelligence compared to those who are not involved, or are involved to a lesser degree, in activities related to digital technologies. Computers and the Internet are shown to enhance motivation for learning new things (Wang \& Braman, 2009), and to help restructure the brain mechanisms involved in retrieval of information units (Small \& Vorgan, 2008), i.e., to take advantage of the "cognitive surplus" (Shirky, 2010).

The cultural-historical theory advanced by Lev Vygotsky and his school of thought provides evidence that the use of external instruments and sign systems results in transformations of the human being's inner psychic activities (Vygotsky, 1978). Thus, information technologies, such as universally used semiotic instruments, are not neutral for mental development. Theoretical and practical arguments and the consequences of this thesis are thoroughly discussed in Tikhomirov's works on the "personal meanings" theory of thinking and on the psychology of computerization (Tikhomirov, 1974; Tikhomirov, 1988; Voiskounsky, 2013), as well as in the works of other adherents to Vygotsky's theory.

Computers and the Internet impact artistic creativity. Entirely new types of contemporary art have already emerged, such as digital art. Virtual environments, such as virtual office images, have been shown to contribute to higher marks in creativity (measured by psychological testing procedures), compared to several types of real-life environments (Guegan et al., 2017); that means, artificial environments 
influence creative processes irrespective of the kinds of interfaces. Image editing software is rapidly changing production processes in the arts. Hypertext structures advance new perspectives for verbal art (Landow, 2016). Digital technologies (e.g., program packages for 3D modeling and simulation) play a crucial role in contemporary visual art and design. Architectural cyber-theory is laying claim to be a theoretical platform for examining the impact of computer technologies on various aspects of design, starting with architectural construction (Kuloglu, 2010).

\section{Computer gaming}

Both adults and adolescences are active users, and sometimes developers, of numerous services and resources on the Internet (Babaeva \& Voiskounsky, 2002). Computer games (we use this as a general term that includes videogames, online games, multiuser roleplay games, browser games, games played on consoles, etc.) are extremely attractive to all ages, partly due to the fact that the games give everyone an opportunity to feel like an inventor while playing them. Ignoring the negative outcomes of computer gaming, such as psychological addiction or the increase of aggressiveness, we will limit our discussion of the possible impact of gameplay to the thinking and creative abilities of adolescents and adults. "Serious games" are being widely developed in order to enhance the quality of teaching and learning (Shaffer, 2007).

There are a number of studies which have examined both the creativity and the thinking abilities of those who play computer games regularly. For example, 12-year-old adolescents who are experienced online gamers have shown higher creativity measures on the Torrance tests compared to their less-experienced peers (Jackson et al., 2012). Gackenbach and Dopko (2012) showed that adults' gaming experience has no influence on their verbal creativity, but positively influences their scores on the Torrance non-verbal creativity test. Young adults who used to be hard gamers and went on playing computer games, are described as becoming effective and competent, though risk-taking, businessmen or stock exchange brokers (Beck \& Wade, 2004).

Computer games can be regarded as a platform for examining the thinking abilities and creative performances of both gamers and game developers, including producers, coders, musicians, experts in animation and computer graphics, and educationalists (Lee \& Peng, 2006; Video games and creativity, 2015). Specially designed games force players to develop and organize mental tools to perform activities within extremely complex virtual environments. In investigating these computer-game-mediated activities, researchers can examine human expertise and abilities to put forward and test hypotheses while solving problems within extremely complex environments (Dörner, 1997).

Numerous studies have revealed some positive influences of computer gaming on cognitive abilities (Greenfield, 2009; Lee \& Peng, 2006; Shirky, 2010). This perspective is nevertheless questionable and warrants a more detailed investigation, as Boot et al. (2008) have suggested. Computer games provide a person with opportunities to intensely use his/her competence and intuition. While intuition often helps to solve problems, it just as frequently leads to mistakes in decision-making (Kerdellant \& Gresillon, 2003; Beck \& Wade, 2004; Usher et al., 2011). 
Among the most promising directions of research on the psychological aspects of computer gaming is the examination of the transfer of gaming skills from the virtual world to the real one (Greenfield, 2009; Lee \& Peng, 2006; Oei \& Patterson, 2015). In the context of cognitive control studies, computer gamers exhibit high competence in the transfer of habits and skills from the game-related virtual world to everyday life (Van Muijden et al., 2012; Anguera et al., 2013). The characteristics of virtual avatars are shown to impact the real-life choices of these avatars' owners (Yee, 2014). Proficiency in 3D computer gaming highly correlates with effectiveness in performing numerous activities, such as driving and learning to perform laparoscopic surgery (Greenfield, 2009; Kerdellant \& Gresillon, 2003), as well as management and business-related activities (Beck \& Wade, 2004).

\section{Electronic brainstorming}

Many Internet projects and multi-person computer games enhance distributed cognition performed by many people simultaneously in parallel ways. In this context, a new type of thinking is expected to emerge, manifesting itself within Internet-mediated activities. It has been called "network (or swarm) thinking," and it relates to so-called "collective creativity" (Tapscott \& Williams, 2006; Woolley et al., 2010), although the latter has not yet gained fundamental psychological validation and should rather be referred to as "hypothetical collective creativity." The key factor in "collective intelligence," as well as a likely element of "collective creativity," is alleged to be the social sensitivity of group members (Meslec et al., 2016).

Digital technologies have been widely adapted to become tools that support the manifestation of individual and group creativity (interconnected computers are an example of these tools). In this context, there is an effective method for generating group creative activity-electronic brainstorming (EBS). Over recent decades, interest in EBS has been increasing. This method possesses some advantages compared to traditional face-to-face brainstorming, since it involves parallel interaction, anonymous work, the opportunity to articulate new ideas immediately upon generating them, the ability to get additional information to produce qualitative ideas, and freedom from apprehension effects (Benedek, Fink, \& Neubauer, 2006; Kerr \& Murthy, 2009; Yagolkovskiy, 2016).

On the other hand, the computer mediation which is specific to EBS, leads to a lack of emotional contact among participants and of opportunities for them to communicate non-verbally. Moreover, it could be rather time-consuming for a participant to type up all the ideas he/she produces on a keyboard. Thus, the specificity of computer mediation as a factor of creative activity may be seen as a promising point for future research, the aim of which will be to examine its potential to stimulate either individual or group creativity.

\section{Minecraft}

Minecraft is one of the most popular computer games. Nowadays, over a hundred million people play this game (https://en.wikipedia.org/wiki/Minecraft). A recent mass survey (Yee, 2015) of gamers' demography and motivation showed that the proportion of females playing Minecraft was slightly higher than the average in a sample of over 100,000 gamers playing diverse computer games; they score high on 
such empirically based motivations as Discovery (interest in experiments and explorations) and Community (interest in interactions and making teams), while low on Excitement (especially fast-paced and intense) and Story (interest in narrative scripts and elaborated characters).

The Minecraft world consists of cube blocks used to construct complex objects. The game has three modes: a creative mode and two modes of survival within hostile worlds. The creative mode provides a gamer with unlimited resources. In both of the survival modes the given resources are limited. Playing Minecraft, as well as similar games such as Second Life, involves construction of fanciful virtual worlds.

The use of Minecraft in psychological research work and practice has been increasing, although not as intensely as Second Life-related studies. Second Life is an older online platform for socializing and demonstrating personal creativity. Minecraft can serve as a means for developing communicative skills and logical thinking (Trcek, 2014; Cipollone, 2014). It may be also used as a learning platform to support educational processes in elementary school (Shaw, 2014).

In fact, we used Minecraft not as a competitive game environment, but as an environment for constructing new objects, or structures-in our case, the objects which the participants believed to be creative. We have chosen Minecraft as a computer environment to access participants' creativity for the following reasons. First, it is not time-consuming to train gamers to play this game. Second, it allows the parameters of participants' playing activities in either individual and group formats to be compared.

\section{Goals}

Our main goal was to explore the prospects for the online interface which has been developed to support productive and creative (1) individual and (2) group work. By prospects we mean that a group (a sort of a "collective intellect") using this interface outperforms a single person. In such a case we will have a tacit proof of the fact that the online interface suggests good prospects for group work.

The present study compared participants' creative productivity while they created new structures using the Minecraft constructive elements, either individually or in dyads.

We hypothesized that the dyadic productivity and originality in constructing complex objects would be more effective than the individual productivity and originality of those involved in performing a similar task.

Since this paper reports on a work in progress, among the goals of the ongoing study is detection of probable cases which may contradict the results and form the basis for subsequent qualitative analysis. If such cases are not found, that may reduce the program of subsequent studies.

\section{Method}

\section{Sample}

The sample consisted of forty-nine participants (29 males and 20 females) between 18 and 29 years of age $(M=22.3, S D=3.26)$. They were recruited via the Internet and personal ties (snow-ball). Most of them were university/college students. All par- 
ticipants were experienced computer users (with proficiency in intensive computer use for no less than five years). All participants got a short online training course on how to play Minecraft, although some were already experienced.

\section{Design}

Each participant performed creative activity under both individual and dyadic (hereafter called group) conditions. Approximately half of them (25 randomly selected participants) performed the given task first in the individual format, and subsequently in the dyadic format; the rest, vice versa. Participants under the dyadic conditions were randomly recruited exclusively from those who either had performed the given task individually, or had not yet participated in the experiment.

\section{Materials and tasks}

The online platform for gaming activity was Minecraft version 1.7.9 (Creative mode). A specially organized Minecraft game server supplied each participant with all the necessary instruments and online resources to play the game. This server was repeatedly re-booted after each online gaming session. All the data from each session was saved on the server.

The initial virtual environment in Minecraft for each participant had been preestablished by experimenters to provide equal starting conditions.

There were two complex objects (structures) to be built: a house and a ship. Each participant built both of these objects: one within the first session, the other within the second session. We chose these objects as the core element of the task because they seemed to be similar in complexity, and are familiar to almost everyone.

Participants used Skype to communicate with each other. Every image on the participants' screens and every sound they made was video- and audio-recorded using the FastStone Capture software package.

\section{Procedure}

\section{Preliminary Minecraft online training}

Participants were preliminarily trained in how to play Minecraft. At the very end of the training course they had to build a trial archway, to test their competence and skills.

\section{The experiment}

Participants logged in from a distant location to the Minecraft game server, and installed Skype and FastStone Capture. They could communicate via Skype with each other, as well as with the experimenters.

The experiment was comprised of an individual and a group session. Each participant performed different tasks in the individual and dyadic format. He/she was randomly assigned to a particular sequence of these sessions and to the first object to be built. There was one-day break between sessions.

All participants were to build complex objects (structures) that had to be creative, i.e. as singular and unique as possible. 
Participants were required to articulate all their ideas and comments aloud. They were aware of being recorded. They could view each other's avatars at all times. Moreover, they were provided with all the visual and audio information on what their partners were doing in real time.

Participants were not given a time limit, but they were aware of the preferred time frame for accomplishing the mission-one hour. Participants got the following verbatim instructions:

Please build a ship/a house which you have never seen. Try to make it as unique, unusual, and original as possible. You can build whatever you want. There are no special requirements about the structure and shape of the construction. Activate the potential of your imagination, throw away all barriers and limitations, and just do it! Upon the completion of the task, please assign an unusual name to the constructed object. Please verbalize aloud everything you are doing at the moment, articulate all your intentions concerning the task, and-this is especially important-express verbally all the ideas you produce. Try to accomplish the mission within one hour. Upon the completion of the mission, please give a guided tour of your house (or your ship) and tell a short story about it.

\section{Coding}

Productivity (personal and dyadic)-i.e., the number of ideas, or goals the participants generated-was measured, as well as the originality of these ideas. In his presidential address to the American Psychological Association, J.P. Guilford (1950) called attention to the importance of productivity (fluency) as a parameter of individual creativity: "...the person who is capable of producing a large number of ideas ..., has a greater chance of having significant ideas" (p. 452). We regard this parameter of creative performance as an important indicator of an individual's productive contribution to the construction of a given complex object.

Certainly, the ideas referred to different levels of the final product, i.e. the development of a ship or a house. According to the "personal meanings" theory (Tikhomirov, 1988), the goal setting structure of the process of decision-making may be empirically classified depending on the role of a particular goal in the whole structure and its closeness to the final outcome. Relying on this tradition, we classified the ideas (i.e., goals) according to different empirical criteria.

For example, in assessing idea generation, we differentiated five types of ideas:

- Conceptual (large-scale ideas concerning the main concept of the object)

- Functional (assigning to an object's non-standard functions)

- Selective (selection of appropriate material and color from the given options)

- Corrective (ideas how to change or re-build various components of the structure)

- Intentional (novel ideas with no proposed practical applications)

The classifications of the types of ideas, as well as what level of the object to be built they referred to, were developed after the pilot work was done and analyzed. These classifications were the product of discussions (and consensus) among all 
four authors. All the mentioned ideas referred to various aspects of the object (i.e., the structure the participants built). They were as follows:

- the whole structure (refers to the house or ship)

- a particular component or part of the structure (walls, ceiling, floor, furniture, sail, etc.)

- $\quad$ an element (smaller parts of the object built).

Two sets of experimental data were obtained. The first set referred to the objects (structures) built; the second set was the data extracted from the audio/video records of the process. All the ideas were articulated by participants in either a positive (referring to enrichments of the structure to be built, e.g. by adding elements) or negative (referring to unwillingness to carry out particular enrichments of the structure to be built) context. Each idea was also marked as either implemented or unimplemented.

The total number of ideas in each category was calculated. Many participants did not follow the experimenter's recommendation to try to accomplish the mission within one hour: Actually, the duration of the sessions in the main experiment varied from 20 minutes to 2 hours. For this reason we used the average number of ideas produced within one minute as the basis for the comparison of the participants' idea generation.

We also assessed the creative quality of the ideas generated. This quality is closely related to the originality of these ideas (Guilford, 1950). To measure the originality of the ideas produced by study participants, we used the Consensual Assessment Technique (CAT) developed by T. Amabile (1982). This technique calls for independent experts to assess the data according to their personal understanding of creativity.

\section{Results}

To process the data, the program package IBM SPSS Statistics 20 was used. The most general parameters of the participants' activities are shown in Table 1. The nonparametric Wilcoxon signed-rank test was used to compare the parameters. To the degree that we obtained results referring to various parameters of the participants' idea generation processes, we present the most important and significant data.

Table 1. Comparison of the parameters of participants' activity across the sessions

\begin{tabular}{lcccccc}
\hline Parameters & $\begin{array}{c}\text { M (ind. } \\
\text { session) }\end{array}$ & $\begin{array}{c}\text { SD (ind. } \\
\text { session) }\end{array}$ & $\begin{array}{c}\text { M (group } \\
\text { session) }\end{array}$ & $\begin{array}{c}\text { SD (group } \\
\text { session) }\end{array}$ & $\begin{array}{c}\text { P } \\
\text { level }\end{array}$ & Z-value \\
\hline $\begin{array}{l}\text { Average duration of } \\
\text { a session, minutes }\end{array}$ & 50 & 32.093 & 69 & 28.013 & 0.001 & -3.402 \\
$\begin{array}{l}\text { Average number of ideas } \\
\text { generated per minute }\end{array}$ & 2.268 & 1.24 & 1.493 & 0.91 & 0 & -3.914 \\
\hline
\end{tabular}

Notes: $\mathrm{M}$ - mean; SD - standard deviation; P - level- the level of significance; Z-value - the Wilcoxon signed-rank test's z-value 
The average duration of the group sessions was significantly longer than the average duration of individual ones. Contrary to our main hypothesis, the participants generated significantly more ideas per minute during individual sessions compared to the group format. Further analysis will show which types of ideas occurred more often in individual sessions compared to group sessions, and possibly vice versa.

In Table 2, the data on the number of ideas of different classification types are presented.

Table 2. The number of ideas of different types across the sessions

\begin{tabular}{lcccccc}
\hline Parameters & $\begin{array}{c}\text { M } \\
\text { (ind. } \\
\text { session) }\end{array}$ & $\begin{array}{c}\text { SD } \\
\text { (ind. } \\
\text { session) }\end{array}$ & $\begin{array}{c}\text { M (group } \\
\text { session) }\end{array}$ & $\begin{array}{c}\text { SD } \\
\text { (group } \\
\text { session) }\end{array}$ & $\begin{array}{c}\mathbf{P} \\
\text { level }\end{array}$ & Z-value \\
\hline Conceptual & 0.935 & 0.49 & 0.619 & 0.379 & 0 & -3.865 \\
Functional & 0.174 & 0.218 & 0.057 & 0.051 & 0 & -4.561 \\
Corrective & 0.48 & $0 ., 383$ & 0.332 & 0.346 & 0 & -3.556 \\
Selective & 0.512 & 0.397 & 0.325 & 0.203 & 0.004 & -2.89 \\
Intentional & 0.166 & 0.172 & 0.165 & 0.131 & 0.762 & -0.303 \\
\hline
\end{tabular}

During individual sessions the participants generated significantly more ideas of all types (except the intentional ideas) than in the group format: the mean number of intentional ideas was about the same in the single and individual formats. Novel non-practical intentions were expressed equally often irrespective of having a partner or not. After we found that ideas were produced more often during the individual sessions, it was useful to learn whether the participants produced proportionally equal (or close to the same) number of ideas in the two formats, at each of the three different levels of the constructions they were building (namely, the levels of the whole structure, components, or elements). Table 3 contains the data on the levels to which the generated ideas referred.

Table 3. The number of ideas referring to different structural levels across the sessions

\begin{tabular}{lcccccc}
\hline & $\begin{array}{c}\text { M (ind. } \\
\text { session) }\end{array}$ & $\begin{array}{c}\text { SD (ind. } \\
\text { session) }\end{array}$ & $\begin{array}{c}\text { M (group } \\
\text { session) }\end{array}$ & $\begin{array}{c}\text { SD (group } \\
\text { session) }\end{array}$ & $\begin{array}{c}\text { P } \\
\text { level }\end{array}$ & Z-value \\
\hline Structure level & 0.088 & 0.091 & 0.099 & 0.092 & 0.135 & -1.494 \\
Component level & 0.477 & 0.313 & 0.328 & 0.177 & 0.007 & -2.711 \\
Element level & 1.589 & 1.051 & 1.073 & 0.752 & 0.001 & -3.477 \\
\hline
\end{tabular}

The data show that during individual sessions the participants generated significantly more ideas on the component and element levels, than in the group format, and insignificantly less on the level of the whole structure. We can suggest that a likely reason for that is that while building a complex object (house or ship) in 
a group, participants were not paying appropriate attention to the small details of the would-be object, such as the interior design and furnishings of the house or the ship; those ideas were significantly more often generated in the individual format. On the contrary, the number of the whole structure ideas generated in the group mode was slightly greater than the number of the same type of ideas produced during individual sessions. We can conclude that the number of global-level ideas about the structure to be built was about the same in the two formats, but the participants felt somehow reluctant and wary of descending to the less global levels such as components, and especially elements. Indeed, ideas dealing with interior decoration seemed to be considered more or less a private matter, and thus were not easily shared with a partner.

Our experiment differs from verbal brainstorming sessions by virtue of the fact that the participants needed to both generate verbalized ideas and construct a virtual structure (a house or a ship) using the Minecraft building blocks. Thus, one of their tasks was to realize their ideas. The data show that many ideas which had been expressed verbally were nevertheless not implemented, either in the individual or group format: these ideas were forgotten and dropped. The two research formats differed in the number of ideas generated and not implemented: the number of unimplemented ideas was significantly higher $(\mathrm{p}<0.0001, \mathrm{Z}=-5.834)$ in the group sessions compared to the individual sessions $(M=0.141, S D=0.123$ for the individual format and $\mathrm{M}=1.565, \mathrm{SD}=1.063$ for the group format).

Participants generated fewer ideas during the group sessions, compared to individual sessions, and at the same time, they dropped more of their ideas. The particular types of ideas ( to which level of the structure they applied) which were more frequently unimplemented in the group format than during the individual sessions, are presented at Table 4.

Table 4. The types of ideas which were more often left unimplemented during group sessions

\begin{tabular}{lcccccc}
\hline & $\begin{array}{c}\text { M (ind. ses- } \\
\text { sion) }\end{array}$ & $\begin{array}{c}\text { SD (ind. } \\
\text { session) }\end{array}$ & $\begin{array}{c}\text { M (group } \\
\text { session) }\end{array}$ & $\begin{array}{c}\text { SD (group } \\
\text { session) }\end{array}$ & P level & Z-value \\
\hline $\begin{array}{l}\text { Functional, } \\
\text { component level }\end{array}$ & 0.0004 & 0.002 & 0.003 & 0.007 & 0.028 & -2.192 \\
$\begin{array}{l}\text { Intentional, } \\
\text { component level }\end{array}$ & 0.006 & 0.014 & 0.017 & 0.024 & 0.003 & -2.93 \\
$\begin{array}{l}\text { Intentional, } \\
\text { element level }\end{array}$ & 0.015 & 0.024 & 0.029 & 0.032 & 0.034 & -2.119 \\
$\begin{array}{l}\text { Corrective, } \\
\text { element level }\end{array}$ & 0 & 0.002 & 0.004 & 0.11 & 0.021 & -2.312 \\
\hline
\end{tabular}

The data in Table 4 show that during the group sessions the participants more frequently dropped (and left unimplemented) ideas referring to the levels of either components or elements of the structure, than they did during the individual sessions. It is important to note that the ideas of the intentional type are among those which were most often not realized (i.e., dropped) during the group format. We 
also can conclude that this type of ideas (intentions) was the only type which was generated equally often in the two formats. More specifically, this conclusion refers to ideas at the component and element level, not at the level of the whole structure.

As mentioned above, we also assessed the originality of the ideas generated. Two psychologists performed the assessments independently, and since the conformity between their assessments turned out to be high $(\mathrm{r}=0.876)$, we consider the result presented in Table 5 to be reliable. Since the duration of particular work sessions, as well as the number of ideas produced by particular participants and dyads, varied, the data in Table 5 are represented as the number of original ideas produced during the session, divided by the general number of ideas produced by a participant or a dyad during the work session.

Table 5. The originality of ideas produced during individual and group sessions

\begin{tabular}{lcccccc}
\hline & $\begin{array}{c}\text { M (ind. } \\
\text { session) }\end{array}$ & $\begin{array}{c}\text { SD (ind. } \\
\text { session) }\end{array}$ & $\begin{array}{c}\text { M (group } \\
\text { session) }\end{array}$ & $\begin{array}{c}\text { SD (group } \\
\text { session) }\end{array}$ & P level & Z-value \\
\hline $\begin{array}{l}\text { Originality/ } \\
\text { number of ideas }\end{array}$ & 0.123 & 0.006 & 0.115 & 0.076 & 0.345 & -0.945 \\
\hline
\end{tabular}

The results show that individuals produced original ideas slightly more often than the dyads, although the difference is insignificant. Thus, we need to accept the fact that both hypotheses of the current study were incorrect. Contrary to our assumptions, individuals are more productive in generating ideas than dyads, and secondly, dyads are not more productive in generating original ideas than individuals. These results lead us to declare that the interface which was developed is not "dyad-friendly;" i.e., it does not push dyads to work productively and in an original manner. This result may be called negative because it means that the interfaces of the future need to differ from the one we have developed.

\section{Discussion}

Both dyadic and individual creative problem-solving has been investigated over decades in academic and applied psychology (to name just a few studies: Amabile, 1996; Doerner, 1997; Guilford, 1950; Lubart, 2001; Osborn, 1957; Tikhomirov, 1988). Rather unexpectedly, the findings produced in the current study show that the productivity of creative performance, measured as the number of generated ideas, was significantly higher in the individual format compared to the dyadic format. This result contradicted our hypothesis about the positive influence of group activity on creative productivity. We have to admit that the finding is partially in line with the results of earlier studies from previous decades, specifically those which revealed that nominal groups outperform interactive groups due to negative group interaction effects, such as the fear of being negatively assessed, conformity, and social loafing (Diehl \& Stroebe, 1987; Lamm \& Trommsdorff, 1973; Mullen, Johnson, \& Salas, 1991; Taylor, Berry, \& Block, 1958).

At the same time, numerous studies have shown that groups are more effective in idea generation than separate individuals (Hwang \& Guynes, 1994; Os- 
born, 1957; Wooley et al., 2010). Since contradictory views have been expressed as well, the available empirical results are controversial. The results presented in the current paper strengthen the positions of those who believe that individuals are more productive than the same individuals combined in small groups such as dyads.

The analysis of the results shows that, under conditions of dyadic creative activity, the participants generated fewer ideas of the conceptual, functional, corrective, and selective type on both the component and element levels. The decrease of idea generation in the dyadic format may be interpreted as the tendency of study participants to let others manage the time needed for performing particular actions (e.g. make a window in the wall built earlier). This effect approximates the social loafing effect and the free-riding effect in group work (Hall, Buzwell, 2013).

To organize and manage online group activity, an aptitude for leadership, as well as the ability to distribute roles and responsibilities within a mission, and a well-developed emotional intelligence, are required (Herodotoua et all., 2011). These requirements are not common within the general population. While participants in the current study were recruited randomly, we can assume that only a few of them met the above mentioned requirements. Thus, it might have been problematic for them to manage the process of dyadic construction of a house or a ship. On the contrary, within the individual sessions, the participants were ready to take responsibility for time management, as well as for the efficiency of idea generation.

Processes of decision making differ in dyadic and individual sessions. Our analysis shows that within dyadic sessions the number of ideas which were implemented was lower $(\mathrm{M}=1.34)$ compared to the individual format $(\mathrm{M}=2.14, \mathrm{Z}=-4.116$, $\mathrm{p}=0.000$ ). Two considerations seem to be relevant.

First, working in dyads, participants generated many ideas-articulated them and discussed them with partners-which were subsequently forgotten or not implemented for other reasons. Quite often these ideas seemed to contradict the partners' plans (as projected in the partners' verbalization of their ideas, or in their practical actions on a computer screen) for the mutual structure to be built, and as a result, impeded joint work by dropping some of these ideas as prospective directions for the further work. This is a type of disadvantage related to interaction at a distance, even in communication-rich cases.

Second, analysis of the protocols shows that during the group sessions, the participants often produced more complicated and challenging ideas than they generated in the individual format, and paid too little attention to the feasibility and applicability of their ideas. In the authors' view, such a decrease of personal responsibility during one's performance in a group approximates the social loafing effect mentioned earlier in this section.

To competently discuss this study's main finding (i.e., that individual work turned out to be more productive and no less original than dyadic work), we undertook one additional analysis of the protocols. This analysis showed that approximately one third of study participants (14 out of 49) were more productive in dyads than in individual sessions. While their dyadic sessions were only 1 minute longer $(69 \mathrm{~min})$ than the average dyadic session $(68 \mathrm{~min})$, they produced more ideas $(M=108)$ than an average value $(M=100)$. As individuals, they produced 
many fewer ideas $(M=76)$ than the average number of ideas in the individual sessions $(M=104)$, working one minute less (48 min against $M=49 \mathrm{~min})$. These 14 participants benefitted from the dyadic sessions; the reasons are possibly connected with their personality traits and preferred interaction modes. Since the study participants were not tested for psychological parameters, we may only guess at which particular personality traits these participants shared. Sources in the literature suggest that these traits may include social intellect (Meslec et al., 2016; Woolley et al., 2010). These results will be eligible for a subsequent qualitative analysis.

The participants performed the study's building tasks in the Minecraft environment, which provided them with opportunities to apply their creativity with minimal limitations and constraints. Live interactions between participants were organized; this is one of the specific features of the design of the current study. The zero-level interface developed for this study does not seem to be the most beneficial for group work to be performed in the near future. Thus, in the studies to follow, more elaborated interfaces need to be developed, very likely including elements of artificial intelligence which would help the study participants by suggesting hints and prompts, producing lists of ideas to discuss, and letting the participants most involved in suggesting prospective ideas and solutions lead the discussion. Even irrespective of the character of the interfaces, special environments may lead research participants "not to produce more ideas, but to explore idea categories in greater depth" (Guegan et al., 2017, p. 4). This is one of the most common ways to enrich the originality of ideas. The environments and the interfaces should complement each other.

\section{Limitations}

The current study had certain limitations. First, although the participants had not been acquainted with each other prior to being combined into dyads, social factors such as teambuilding or attitudes towards their partners were not observed, fixed, and analyzed. Second, the use of Skype as a means of interaction between the participants during group sessions, as well as the observation of the partners' avatars, reduced the quantity and quality of emotional contacts during the sessions. This format of creative activity does not have the possible advantages peculiar to an electronic brainstorming session (EBS); thus the next research question is to learn whether the EBS-related findings are relevant to the conditions of the current study. Third, the interface that had been developed was not friendly to the group style of work, and thus it needs to be enriched for future studies.

\section{Conclusion}

Here are the most important conclusions of the study:

1. Within the dyadic sessions, participants produced ideas less intensely and consumed more time in accomplishing their missions than they did during individual sessions.

2. Participants working in dyads generated fewer ideas on components and elements (but not on the whole structure). 
3. When working in dyads rather than in individual sessions, participants tended to produce more ideas which were subsequently unimplemented, and fewer ideas of some categories that were subsequently implemented.

4. The perspective for generating original ideas in dyads is great enough; while the number of ideas produced by dyads is less than the number of ideas produced individually, the number of original ideas is about the same in the two types of work. Thus, if we find ways to enrich the interface, we have a good chance of developing interfaces which will make dyadic work more beneficial than the individual style of work.

\section{Acknowledgements}

This research was supported by the Russian Foundation for Basic Research (project № 15-06-06168) and the Program of Basic Research at the National Research University Higher School of Economics.

\section{References}

Amabile, T.M. (1996). Creativity in context. Boulder, CO: Westview Press.

Amabile, T.M. (1982). Social psychology of creativity: A consensual assessment technique. Journal of Personality and Social Psychology, 43, 997-1013. doi: 10.1037/0022-3514.43.5.997

Anguera, J.A., Boccanfuso, J., Rintoul, J.L., Al-Hashimi, O., Faraji, F., Janowich, J., ..., \& Gazzaley, A. (2013). Video game training enhances cognitive control in older adults. Nature, 501, 97-101. doi: 10.1038/nature12486

Babaeva, J.D., \& Voiskounsky, A.E. (2002). IT-giftedness in children and adolescents. Educational Technology \& Society, 5(1), 154-162.

Beck, J. S., \& Wade, M. (2004). Got game: How the gamer generation is reshaping business forever. Harvard Business Review Press.

Benedek, M., Fink, A., \& Neubauer, A.C. (2006). Enhancement of ideational fluency by means of computer-based training. Creativity Research Journal, 18, 317-328. doi: 10.1207/ s15326934crj1803_7

Boot, W.R., Kramer, A.F., Simons, D.J., Fabiani, M., \& Gratton, G. (2008). The effects of video game playing on attention, memory and executive control. Acta Psychologica, 129, 387-398. doi: 10.1016/j.actpsy.2008.09.005

Cipollone, M., Schifter, C.C., \& Moffa, R.A. (2014). Minecraft as a Creative Tool: A Case Study. International Journal of Game-Based Learning, 4(2), 1-14. doi: 10.4018/ijgbl.2014040101

Dailey, L., \& Mumford, M.D. (2006). Evaluative aspects of creative thought: Errors in appraising the implications of new ideas. Creativity Research Journal, 18(3), 367-384. doi: 10.1207/ s15326934crj1803_11

Diehl, M., \& Stroebe, W. (1987). Productivity loss in brainstorming groups: Toward the solution of a riddle. Journal of Personality and Social Psychology, 53(3), 497-509. doi: 10.1037/00223514.53.3.497

Dörner, D. (1997). The logic of failure: Recognizing and avoiding error in complex situations. New York: Metropolitan Books.

Estes, Z., \& Ward, J.B. (2002). The emergence of novel attributes in concept modification. Creativity Research Journal, 14, 149-156. doi: 10.1207/S15326934CRJ1402_2

Gackenbach, J., \& Dopko, R. (2012). The relationship between video game play, dream bizarreness, and creativity. International Journal of Dream Research, 5(1), 23-36. 
George, J.M., \& Zhou, J. (2001), When openness to experience and conscientiousness are related to creative behavior: An interactional approach. Journal of Applied Psychology, 86, 513-524. doi: $10.1037 / 0021-9010.86 .3 .513$

Greenfield, P. M. (2009). Technology and informal education: What is taught, what is learned. Science, 323(2), 69-71. doi: 10.1126/science. 1167190

Gruys, M.L., Munshi, N.V., \& Dewett, T.C. (2011). When antecedents diverge: Exploring novelty and value as dimensions of creativity. Thinking Skills and Creativity, 6(2), 132-137. doi: 10.1016/j.tsc.2011.01.005

Guegan, J., Nelson, J., \& Lubart, T. (2017). The relationship between contextual cues in virtual environments and creative processes. Cyberpsychology, Behavior, and Social Networking, 20(3), 1-5. doi: 10.1089/cyber.2016.0503

Guilford, J.P. (1950). Creativity. American Psychologist, 5(9), 444-454. doi: 10.1037/h0063487

Hall, D., \& Buzwell, S. (2013). The problem of free-riding in group projects: Looking beyond social loafing as reason for non-contribution. Active Learning in Higher Education, 14(1), 37-49. doi: 10.1177/1469787412467123

Herodotoua, C., Kambourib, M., \& Winters, N. (2011). The role of trait emotional intelligence in gamers' preferences for play and frequency of gaming. Computers in Human Behavior, 27(5), 1815-1819. doi: 10.1016/j.chb.2011.04.001

Hunter, S.T., Bedell-Avers, K.E., Hunsicker, C.M., Mumford, M.D., \& Ligon, G.S. (2008). Applying multiple knowledge structures in creative thought: Effects on idea generation and problemsolving. Creativity Research Journal, 20(2), 137-154. doi: 10.1080/10400410802088779

Hwang, H.-G., \& Guynes, J. (1994). The effect of group size on group performance in computersupported decision making. Information \& Management, 26, 189-198. doi: 10.1016/03787206(94)90092-2

Jackson, L.A., Witt, E.A., Games, A. I., Fitzgerald, H.E., Eye, A., \& Zhao, Y. (2012). Information technology use and creativity: Findings from the Children and Technology Project. Computers in Human Behavior, 28, 370-376. doi: 10.1016/j.chb.2011.10.006

Kaufmann, G. (2003). Expanding the mood-creativity equation. Creativity Research Journal, 15, 131-135. doi: 10.1080/10400419.2003.9651405

Kerdellant, Ch., \& Gresillon, G. (2003). Les Enfants-puce. Comment Internet et les jeux vidéo fabriquent les adultes de demain. Paris: Denoël (in French).

Kerr, D., \& Murthy, U. (2009). The effectiveness of synchronous computer-mediated communication for solving hidden-profile problems: Further empirical evidence. Information \& Management, 46(2), 83-89. doi: 10.1016/j.im.2008.12.002

Kuloglu, N., \& Asasoglu, A.O. (2010). Indirect expression as an approach to improving creativity in design education. Procedia Social and Behavioral Sciences, 9, 1674-1686. doi: 10.1016/j. sbspro.2010.12.384

Lamm, H., \& Trommsdorff, G. (1973). Group versus individual performance on tasks requiring ideational proficiency (brainstorming): A review. European Journal of Social Psychology, 3(4), 361-388. doi: 10.1002/ejsp.2420030402

Landow, G. (2006). Hypertext 3.0: Critical theory and new media in an era of globalization. Baltimore: Johns Hopkins University Press.

Lee, K.W., \& Peng, W. (2006). What do we know about social and psychological effects of computer games? A comprehensive review of current literature. In P. Vorderer \& Bryant J. (Eds.), Playing video games. Motives, responses and consequences. (pp. 325-346). Mahwah: Lawrence Erlabaum.

Lubart, T.I. (2001). Models of the creative process: Past, present, and future. Creativity Research Journal, 13, 295-308. doi: 10.1207/S15326934CRJ1334_07 
Martindale, C. (1999). Biological bases of creativity. In R.J. Sternberg (Ed.), Handbook of creativity. (pp. 137-152). Cambridge: Cambridge University Press.

Meslec, N., Aggarwal, I., \& Curseu, P.L. (2016). The insensitive ruins it all: Compositional and compilational influences of social sensitivity on collective intelligence in groups. Frontiers in Psychology, 7, 676. doi: 10.3389/fpsyg.2016.00676

Muijden, V.J., Band, G.P. H., \& Hommel, B. (2012). Online games training aging brains: Limited transfer of cognitive control functions. Frontiers in Human Neuroscience, 6(221). doi: 10.3389/fnhum.2012.00221

Mullen, B., Johnson, C., \& Salas, E. (1991). Productivity loss in brainstorming groups: A meta-analytic integration. Basic and Applied Social Psychology, 12(1), 3-23. doi: 10.1207/ s15324834basp1201_1

Obsorn, A. F. (1957). Applied imagination. N.ew York: Scribner.

Oei, A.C., \& Patterson, M.D. (2015). Enhancing perceptual and attentional skills requires common demands between the action video games and transfer tasks. Frontiers in Psychology, 6 . doi: 10.3389/fpsyg.2015.00113

Rich, J.D., \& Weisberg, R.W. (2004). Creating all in the family: A case study in creative thinking. Creativity Research Journal, 16, 247-259. doi: 10.1080/10400419.2004.9651456

Russ, S. (2003). Creativity research: Whither thou goest. Creativity Research Journal, 15, $143-$ 145. doi: 10.1080/10400419.2003.9651407

Scott, G.M., Lonergan, D.C., \& Mumford, M.D. (2005). Contractual combination: Alternative knowledge structures, alternative heuristics. Creativity Research Journal, 17, 21-36. doi: 10.1207/s15326934crj1701_7

Shaffer, D.W. (2007). How computer games help children learn. London: Palgrave Macmillan.

Shaw, E., La, M. T., Phillips, R., \& Reilly, E.B. (2014). PLAY Minecraft! Assessing secondary engineering education using game challenges within a participatory learning environment (Research to Practice). (pp. 15-18). 121st ASEE Annual Conference \& expositions.

Shirky, C. (2010). Cognitive surplus: Creativity and generosity in a connected age. New York; London: Penguin Books.

Small, G., \& Vorgan, G. (2008). iBrain: Surviving the technological alternation of the modern mind. Harper Collins.

Tapscott, D., \& Williams, A.D. (2006). Wikinomics. How mass collaboration changes everything. New York; London: Penguin.

Taylor, D.W., Berry, P.C., \& Block, C.H. (1958). Does group participation when using brainstorming facilitate or inhibit creative thinking? Administrative Science Quarterly, 3, 23-47.

Tikhomirov, O.K. (1974). Man and computer: The impact of computer technology on the development of psychological processes. In D.E. Olson (Ed.), Media and symbols: The forms of expression, communication, and education (pp. 357-382). Chicago: University of Chicago Press.

Tikhomirov, O.K. (1988). Psychology of thinking. Moscow: Progress.

Trcek, F. (2014). "The World of MINECRAFT is cubic": LEGO Blocks for E-Kids? Teorija in praksa, 1, 162-178.

Usher, M., Russo, Z., Weyers, M., Brauner, R., \& Zakay, D. (2011). The Impact of the mode of thought in complex decisions: Intuitive decisions are better. Frontiers in Psychology, 2. doi: 10.3389/fpsyg.2011.00037

Green, G., \& Kaufman, J.C. (Eds.). (2015). Video games and creativity: Explorations in creativity research. New York: Academic Press.

Voiskounsky, A.Ye. (2013). Psychology of computerization as a step towards the development of cyberpsychology. Psychology in Russia: State of the Art, 6(4), 150-159. doi: 10.11621/ pir.2013.0413 
Vygotsky, L.S. (1978). Mind in society: The development of higher psychological processes. Cambridge, Mass.: Harvard University Press.

Wang, Y. \& Braman, J. (2009). Extending the classroom through Second Life. Journal of Information Systems Education, 20(2), 235-248.

Woolley, A.W., Chabris, C.F., Pentland, A., Hashmi, N., \& Malone, T.W. (2010). Evidence for a collective intelligence factor in the performance of human groups. Science, 330, 686-688. doi: 10.1126/science.1193147

Yagolkovskiy, S.R. (2016). Stimulation of individual creativity in electronic brainstorming: Cognitive and social aspects. Social Behavior and Personality, 44(5), 761-766. doi: 10.2224/ sbp.2016.44.5.761

Yee, N. (2015). Quantic foundry. Audience profile Minecraft. Retrieved from: http://quanticfoundry.com/2015/09/04/game-audience-profiles/

Yee, N. (2014). The Proteus Paradox: How online games and virtual worlds change us-and how they don't. New Haven \& London: Yale University Press.

Original manuscript received October 16, 2015 Revised manuscript accepted May 26, 2017

First published online November 30, 2017 